
Motrivivência
v. 26,
n. 42,
p. 161-174, junho/2014

\title{
SONHOS NO (DE) GELO: a análise fílmica na perspectiva da estética lukacsiana
}

\author{
Carlos Henrique Ferreira Magalhães \\ Deiva Mara Delfini Batista² \\ Jeferson Diogo Garcia ${ }^{3}$
}

\section{RESUMO}

O objetivo central deste estudo é realizar a análise do filme "Sonhos no gelo", do diretor americano Tim Fywell (2005), a partir da estética Marxista proposta por Georg Lukács (1978). Este objetivo se desenvolve a partir do projeto de pesquisa das "fontes áudio imagéticas". O estudo possui caráter qualitativo, que por meio de uma sinopse interpretativa, busca trazer as categorias da universalidade, singularidade e particularidade de Lukács como base de reflexão e interpretação. Sobretudo, nossa intenção com a analise deste filme é promover subsídios para o professor refletir, de forma contextualizada a questão do esporte, da escola, da relação professor/técnico/ aluno/conhecimento em uma sociedade regida pelo capital por meio da análise fílmica.

Palavras-chave: Esporte; Capitalismo; Cinema; Ética.

1 Doutor em Educação. Professor Adjunto da Universidade Estadual de Maringá. Maringá/Paraná, Brasil.

E-mail: henryferrer@gmail.com

2 Mestre em Educação. Professora Assistente do Departamento de Educação Física da Universidade Estadual de Maringá. Maringá/Paraná, Brasil.

E-mail: dmdbribeiro@uem.br

3 Mestrando em Educação. UEM, Maringá/Paraná, Brasil.

E-mail: jefersondiogogarcia@gmail.com 


\section{INTRODUÇÃO}

As fontes áudio imagéticas, particularmente os filmes cinematográficos, são o objeto de estudo em um projeto de pesquisa que prevê a analise de filmes selecionados e cadastrados para compor um acervo, objetivando disponibilizar os mesmos como subsídio para o trabalho docente no ensino fundamental, médio e superior.

O estudo ${ }^{4}$ é de caráter qualitativo. Estudou-se as sinopses interpretativas de filmes e/ou documentários editados pela indústria cinematográfica. Deste modo, corroboramos com Silva (2004, p.13) quando destaca que "o problema não está no recurso tecnológico em si, porém na maneira como ele é produzido e consumido", ou seja, os filmes da mesma forma que as demais mercadorias, são consumidos como forma de entretenimento, sem que haja qualquer reflexão acerca do contexto do mesmo.

Perante isto, acreditamos que a análise interpretativa deste filme pode servir no processo de mediação para a apropriação do conhecimento em Educação Física, assim como na Educação. Os filmes cinematográficos podem ser utilizados como oportunidade de entender a própria sociedade e as relações sociais correspondentes. O professor poderá utilizar tais materiais de modo a planejar suas atividades, pois o conteúdo de um filme, seja de forma explícita ou implícita, pode levar a momentos de reflexão crítica.

Inversamente, se utilizar os filmes sem criticidade, sem escolha consciente e critério, perde-se de vista uma possibilidade de mediação, que é o objetivo fundamental do nosso projeto, ou seja, problematizar a sociedade rediga pelo capital tendo as fontes áudio-imagéticas como recurso, assim como discutir as possibilidades de superação do capitalismo.

É nesse processo de mediação, e por meio das fontes áudio-imagéticas (filmes) que o professor exerce sua função mediadora entre o conhecimento historicamente produzido e apropriação deste pelos alunos, de modo a proporcionar seu desenvolvimento humano. Deste modo, optou-se para o projeto de pesquisa pela apresentação dos filmes como instrumentos para o processo de mediação da aprendizagem. Entretanto, faz-se necessário um maior entendimento sobre cinema.

Machado (1997) nos apresenta a história do cinema afirmando e enfatizando que "o desejo e a procura do cinema são tão velhos quanto à civilização de que somos filhos". Neste sentido, o cinema enquanto uma produção cultural humana tende a acompanhar o desenvolvimento histórico e tecnológico da humanidade. Exemplo disso são as mais diversas técnicas utilizadas desde a sua invenção até a produção dos filmes na atualidade. Isso fica evidente nos dizeres de Aranha (1996), ao falar que os homens criam novas tecnologias por meio de suas experiências e pelas necessidades do capital. A partir disto, podemos fazer uma analogia com o cinema que, por ser uma mercadoria, está ligada ao "jogo de influências do capital", influenciando o processo de cultura, trabalho, produção e reprodução humana.

4 Este artigo não contou com financiamento. 
Partimos do pressuposto de George Lukács (1978) de que as questões econômicas são fundantes das questões extraeconômicas, porém, estas mantém algum grau de autonomia em alguns momentos. Não se trata de uma relação de causa e efeito, mas de compreender que a reprodução social possui mediações elaboradas de acordo com as condições objetivas, cujo aspecto fundante é o trabalho. Entendemos, de acordo com Lukács (1978a) que a política, o estado, a educação, a arte, entre outros, são complexos extra-econômicos que possuem uma dependência ontológica em relação à economia-política, assim como, em alguns momentos apresentam um grau de autonomia relativa. Isto se deve as contradições em nossa sociedade a qual por vezes faz com que tenhamos uma individualidade, temporariamente distinta, daquela que caracteriza predominantemente a formação do ser social sob a égide do capital, quais sejam: o individualismo, o egoísmo e a competitividade. Vale destacar que estas características desumanas não ocorrem em virtude do livre arbítrio dos homens, mas são fundadas na economia-política capitalista, que corrobora intensamente com uma formação reificada para manter o atual modo de produção e reprodução social (MÉSZÁROS, 2002, LESSA, 2007).

\section{O singular, o particular e o universal: a apreensão do concreto}

Para compreendermos a realidade em sua concretude é necessário entender a História do objeto. Para tanto, nos baseamos nas três categorias de análise propostas por Lukács (1978) que possibilitam uma leitura da realidade, construída pela práxis humana, que é determinada pelas condições materiais de existência.

No processo de estudo da realidade, o fenômeno que se pretende conhecer (que pode ser: a sociedade capitalista, a saúde pública, o lazer, a educação, o trabalho, o esporte, dentre outros), inicialmente se apresenta ao pesquisador como real imediato, pela sua aparência, como visão caótica. Tal fenômeno, em sua aparência, é também um concreto sensível, porque pode ser captado pelos sentidos mais imediatos que é abstrato, porque, na verdade, pouco se sabe dele (fenômeno), em um primeiro contato.

Assim, deste fenômeno busca-se conhecer suas múltiplas determinações (particularidades) que o determinam, para então chegar ao concreto pensado. Destacamos que a universalidade tem seu aspecto fundante na economia-política (LUKÁCS, 1978).

Com efeito, faz-se necessário uma discussão das categorias da universalidade, particularidade e singularidade, bem como a mediação entre elas no processo de caminhar da aparência ao concreto (LUKÁCS, 1978).

Para este autor o "movimento do singular ao universal e vice-versa é sempre mediado pelo particular". Tais categorias:

[...] não são formas lógicas primárias que de algum modo se "apliquem" à realidade, mas sim os reflexos de situações objetivas da natureza e na sociedade, que devem ser confirmadas na práxis humana a fim de se tornarem - através de um posterior processo de abstrações, que todavia, jamais deve perder o contato com a realidade e com a práxis objetiva. (LUKÁCS, 1978, p.69).

A singularidade nos mostra aquilo que é próprio do objeto de estudo, ou seja, o nosso imediato e ocular. Percebemos assim, 
como a característica singular é específica ao objeto de estudo, aquilo que ele possui e que lhe é próprio.

A categoria universalidade compreende os elementos que tem as mesmas propriedades. Todas as características que compõem a universalidade estão relacionadas ao gênero humano. $\mathrm{O}$ aspecto fundante do gênero humano é a economia-política. Dela se produz a riqueza humana em qualquer sociedade. Os demais complexos extraeconômicos (saúde, educação, lazer, esporte, arte, entre outros) possuem uma dependência ontológica em relação à economia-política, porém com uma autonomia relativa. Assim entendemos com Lukács (1979) que o gênero humano relaciona-se ao trabalho, o qual numa sociedade emancipada humanamente, de acordo com Marx (1991) exige o trabalho associado Isso promoveria a liberdade para os homens, ou seja, seu tempo livre para estabelecer o seu desenvolvimento humano, correspondendo ao gênero humano e a universalidade preconizadas em Lukács (1978) e Marx (1991).

Com efeito, para elaborarmos a nossa análise do filme "Sonhos no Gelo" buscamos fazer uma reflexão das primeiras impressões do filme para designar a sua singularidade, particularidade e sua universalidade. Na singularidade do filme identificamos a patinadora no seu desenvolvimento como ser social. Contudo, ser uma patinadora não se constitui num ato isolado de outras mediações que constituem a formação humana. Mediações essas que estão no plano da particularidade e da universalidade. São diversos complexos que se relacionam, intervindo na formação humana. No filme, observamos que para ser uma patinadora campeã, o pressuposto que para alcançar a vitória com quaisquer meios está fundamentando as ações predominantes da treinadora com os seus atletas. Deste modo, para o desenvolvimento deste artigo, consideramos a ética como a particularidade a ser tratada. Quanto à universalidade consideramos os aspectos da economia-política estadunidense da década de 2000 na qual se desenvolve o cenário do filme. Assim entendemos com Lukács que:

A aproximação dialética no conhecimento da singularidade não pode ocorrer separadamente das suas múltiplas relações com a particularidade e com a universalidade. Estas já, em si, contidas no dado imediatamente sensível de cada singular, e a realidade e a essência deste só podem ser exatamente compreendidas quando estas mediações (as relativas particularidades e universalidades) ocultas na imediaticidade forem postas a luz (LUKÁCS, 1978, p.98).

Desse modo, entender quais os pressupostos que atuam na singularidade de ser patinadora numa sociedade regida pelo capital exige-nos buscar o processo de formação do ser social na atual sociabilidade.

\section{Análise fílmica}

O filme "Sonhos no Gelo" é uma produção cinematográfica do diretor americano Tim Fywell (2005), classificado como gênero de comédia e trata da história de uma adolescente americana Casey (Mychelle Tratehtenberg) estimulada por Bart (Steve Ross), seu professor de física, para obter bolsa de estudos e ser aluna de Harvard. Para isto, ela precisa apresentar um projeto, cuja inspiração ela extrai de um campeonato de patinação artística, acreditando que deveria existir uma fórmula aerodinâmica exata para os movimentos acrobáticos específicos da 
patinação no gelo. Assim, ela se envolve com um grupo de patinação e acaba tendo um maior contato com o esporte, a ponto de considerar a Física como algo menos importante no processo.

Para a análise tomamos como singularidade do filme Lukács, (1978b) a questão do "ser patinadora" e por particularidade compreendemos as relações éticas na formação do ser patinadora e a universalidade a sociedade regida pelo capital.

A patinação artística é uma atividade humana que nasce na Europa no século XIV, com patins de madeira, mas se transforma em desporto na Escócia, no século XVI com patins de ferro.

A conotação artística foi dada pelo americano Jackson Haines, no século XIX, introduzindo elementos como a música, a coreografia e a dança na patinação no gelo.

Com essas características, o esporte fez parte das olimpíadas de verão em 1908 em Londres e passou a integrar os jogos olímpicos de inverno na primeira edição em Chamonix, na França em 1924.

Como todo esporte de rendimento, a patinação exige habilidades gerais e específicas, tais como: equilíbrio, flexibilidade, coordenação, força, dentre outros, como também possui seus elementos técnicos: os peões, os saltos e as elevações, que requerem um nível técnico apurado. É nesse sentido que a personagem se inspira para estudar, a partir da Física, as formas aerodinâmicas para a sua execução (FEDERAÇÃO PORTUGUESA DE DESPORTO, 2010).

No entanto, para o seu estudo, a personagem Casey começa a praticar o esporte para aplicar seus conhecimentos por meio de sua prática, no qual, acaba se envolvendo ao ponto de tornar-se atleta entrando em conflito com a sua condição de estudante de Física. Nesse envolvimento com a patinação, ela se depara com um cenário egoísta, traiçoeiro e covarde (KOSIK, 1968). Essa situação demonstra a contradição entre competição e competitividade. $\mathrm{Na}$ competição, subtende-se existir respeito às regras, diferentemente da competitividade, que se remete ao "vale-tudo" para conquistar a vitória (MARQUES JÚNIOR, 2012).

A relação entre ética e a competitividade, não diz respeito especificamente ao esporte, mas a todas as formas institucionais que deveriam estar centrados na formação humana e que, pelo modo de produção capitalista isto não ocorre. Há um processo de formação em que o ser social é predominantemente estranho a si mesmo, estranho aos outros e estranho à realidade (MARX, 2004) nos distintos complexos extra econômicos como tais como a educação, a arte, a política e também o esporte.

\section{As condições éticas no atual modo de produção e reprodução social}

A tese de Lukács citada por Lessa (2007) aponta que numa sociedade regida pelo capital a questão ética se torna impossibilitada. Isto, a grosso modo, pode parecer absurdo, haja vista que as relações humanas sempre foram permeadas por algum modelo ético preconizados em diferentes espaços e tempos históricos, consubstanciados em paradigmas filosóficos, políticos, econômicos, dentre outros.

Lukács indica-nos que a formação humana acontece numa sociabilidade regida pelo capital de forma contraditória. No seu final de vida, por volta da década de 1960, entendeu que deveria fazer uma obra para tratar da ética. Todavia, reconheceu que antes de elaborar esse trabalho 
precisava entender como se formava o ser social. Com isso produziu alguns rascunhos, com cerca de 1000 páginas, que se tornou a sua última obra: $A$ Ontologia do Ser Social (LUKÁCS, 2010). Como se forma o ser social? Essa era uma pergunta básica para que ele pudesse tratar da ética. Afinal, Lukács esteve na União Soviética sob o comando de Josef Vissarionovitch Stalin (1999). Percebeu o quanto o Estado soviético se burocratizou, visto que Marx defendia a superação do Estado preconizando que numa sociedade comunista os trabalhadores deveriam ser livremente associados (MÉSZÁROS, 2002). Observando que os trabalhadores não eram livres, Lukács entendia que aquela organização tinha problemas, sejam institucionais ou daqueles que promoviam a formação do ser social.

Numa sociedade para além do capital, conforme apregoou Mészáros (2002), um dos melhores alunos de Lukács, os homens não deveriam ter hierarquia entre si, assim como a sociedade não deveria ser regulada pelo Direito. Com isso Lessa (2007) indica que o Direito defende a propriedade dos meios de produção da classe burguesa e não o direito da classe trabalhadora. Este autor ainda apoiado em Lukács defende que numa sociedade para além do capital, os homens deverão ser regulados pela ética e não pelo direito. A ética nesse caso corresponde à defesa dos valores que compõem o gênero humano. Todos querem um trabalho, todos querem uma moradia, todos querem uma alimentação, todos querem ter um momento de lazer, o qual somente será conquistado numa sociedade onde os trabalhadores sejam livremente associados num modo de produção para além do capital, conforme apregoou Mészáros (2002).
Com efeito, observa-se que no atual modo de produção o grau de estranhamento que os homens tem em relação a si e em relação à realidade não os permite identificar com clareza que os problemas que vivemos são comuns à classe trabalhadora. Todos os problemas advindos da falta de condições objetivas, não nos permitem comprar uma educação de qualidade, um plano de saúde com qualidade, um pacote de lazer com qualidade. Isto se deve ao fato que nessa sociedade tudo aquilo que possuir valor de uso e valor de troca torna-se mercadoria. Deste modo, a compra dessas mercadorias acontecerá de acordo com a competência particular que cada indivíduo tenha conquistado (sic). Assim observa-se o atual modo de produção ao provendo que os homens se coisifiquem e as coisas se humanizem faz-nos com que assumamos predominantemente valores egoístas, traiçoeiros e covardes. Assim a particularidade de cada indivíduo é estimulada em detrimento do gênero humano que seria a defesa de todo o bem da humanidade e não só o bem particular. Esse modo de ser só interessa a classe burguesa. Afinal ela é uma classe que não pensa no bem da humanidade. E sim no seu bem particular. Por isso acreditamos que Marx e Engels (2007) na Ideologia Alemã estavam coerentes quando afirmavam que as idéias dominantes são produzidas pela classe dominante. A classe trabalhadora pensa e age predominantemente com as idéias produzidas pela classe burguesa. Assim assumimos uma subjetividade inautêntica a qual intensifica que defendamos nossa particularidade em detrimento da generacidade. Com isso Lessa (2007) apoiado em Lukács indica-nos que nessa sociedade os homens não são mediados pelo gênero humano e sim pela particularidade. A ética corresponde à defesa do gênero humano. 
As condições objetivas da sociedade Estado-Unidense na década de $\mathbf{2 0 0 0}$

Entendemos que as características subjetivas indicadas pela treinadora de patinação, no filme em questão, não são peculiares aquela especificidade, mas sim necessárias para a reprodução sóciometabólica do capital.

Daí a necessidade de entender o aspecto fundante da economia-política do capital na década de 2000 no contexto estadunidense a fim de analisar os aspectos extra-econômicos que ele proporciona neste caso a singularidade de ser patinadora e a particularidade da questão ética.

É notório que nos anos de 20002001 e 2008-2009 os noticiários mundiais anunciaram a crise econômica estadunidense. Porém, precisamos ir para além daquilo que fora noticiado pelos meios de comunicação, até porque estes, predominantemente, são representantes do capital. Buscamos a fundamentação em Martins (2005), Mészáros (2002, 2004) e Marx (2004), para entender a atual crise periódica de superprodução do capital.

Antes de mais nada precisamos ter como pressuposto que o capital precisa do trabalho e não o contrário. Caso queiramos entender com radicalidade a crise do capital precisamos entender com radicalidade o trabalho que é a fonte de mais valia absoluta e mais valia relativa necessária para conter a queda da taxa de lucro do capital. O problema desta queda não é a falta de pagamentos de imóveis ou de carros por parte de consumidores conforme os meios de comunicação tanto exploraram na mídia. Isso é a falta de realização do capital.

A produção do capital não se dá com a venda de mercadorias conforme o imaginário social acredita. Isso é a realização do capital. A produção de mais valia se dá na produção da mercadoria na fábrica. É do trabalho que se retira a mais valia absoluta e a mais valia relativa, ou seja, é aqui se expande o capital ou ele se retrai. A mais valia absoluta acontece quando aumentamos a jornada de trabalho, ou seja, as famosas horas extras. A mais valia relativa é produzida quando aumentamos a produtividade do trabalhador por hora. Isso acontece empregando um aporte maior de tecnologia com o capital constante (máquinas) ou com a descoberta de alguma peculiaridade na produção que permita reduzir o tempo de produção de algum componente de alguma mercadoria. É disso que sobrevive o capital e não da venda de mercadorias. A venda é a realização da taxa de lucro extraída do trabalho que está embutida no preço.

Pois bem, o que aconteceu na economia estadunidense, japonesa e alemã que tanto foi anunciado pela mídia internacional não corresponde a uma análise radical. Para isso vamos nos apoiar Martins (2005) Mészáros (2002; 2005). Martins (2005) recorre a dados estatísticos a respeito da produtividade que são divulgados pelo Departamento de Trabalho estadunidense. O Departamento do Trabalho estava mapeando os índices de utilização do capital constante (máquinas, entre outros) a qual é designada por produção/hora. A produção por hora norte americana alcançou seu nível máximo em 2007 (5.9). No ano de 2008 ela caiu significativamente chegando ao final do ano com o índice de 1.9. Basicamente as indústrias de bem duráveis começaram a trabalhar com cerca de $65 \%$ da sua capacidade produtiva. Essa capacidade produtiva estadunidense superou os três trilhões de dólares na produção de mais valia, bem 
distante da nossa $12^{\circ}$ economia mundial (Brasil) a qual sua produção de mais valia não ultrapassa 230 bilhões de dólares por ano. Uma pequena oscilação na economia estadunidense, seja positiva ou negativa, produz repercussões significativas em toda economia mundial.

Assim, se a produção industrial estadunidense estava diminuindo, o que isso poderia provocar? A mais valia produzida pelo trabalho e embutida no preço da mercadoria não estava sendo realizada. Com isto, no período de ascensão da economia criam-se facilidades no crédito para os compradores ao mesmo tempo em que os grandes grupos empresariais tomam de empréstimo, significativas quantias visando aprimorar o seu capital constante necessário para aumentar a produtividade e a mais valia relativa. Assim, o problema aconteceu quando a mais valia não era realizada. Isso exige que a "galinha dos ovos de ouro", o trabalho, na produção industrial entre em queda promovendo uma drástica queda da taxa de mais valia. As conseqüências todas são noticiadas: 1) aumento do desemprego, 2) queda da bolsa de valores, 3) e os significativos empréstimos do Estado para salvar os representantes do capital.

O déficit orçamentário dos Estados Unidos explodiu em março com queda dos impostos pagos pelas empresas e indivíduos e com gastos sobre receitas subiu para $U \$ \$ 192,3$ bilhões, comparada ao déficit de $U \$ \$ 48,2$ bilhões do mesmo mês do ano passado. Os gastos subiram para U\$\$321,2 e as receitas caíram para U\$ $\$ 129$ bilhões. O déficit dos primeiros seis meses do ano fiscal anterior de 2008/2009 já supera o recorde dos doze meses completos do ano fiscal anterior de 2007/2008. O aumento do desemprego e o desabamento dos lucros das empresas estão cortando internamente as receitas de impostos, enquanto o governo transfere bilhões de dólares para sustentar uma economia no seu ano de recessão (MARTINS, 2009).

Esta é uma constatação para definir o papel do Estado já proferido por Karl Marx em 1843: defender o capital. Netto e Braz (2007) corroboram com esta assertiva:

Na medida em que o Estado é comandado pelos interesses do Capital, não é preciso muito esforço para verificar que a destinação dos fundos públicos atende prioritariamente a tais interesses - ou seja, o orçamento é geralmente utilizado como um instrumento que repassa renda dos trabalhadores alocados à produção aos capitalistas e aos segmentos improdutivos (2007, p.121).

Com efeito, entende-se empiricamente o papel do Estado na economia-política estadunidense que destinou o seu fundo público para salvar da bancarrota diversos representantes do capital, dentre eles a General Motors.

Este aspecto da economia-política promove a (de) formação do ser social, pois as condições objetivas são "formadoras" das condições subjetivas, predominantemente. Se o trabalho é fundante da riqueza da humanidade, este, no entendimento do capital, precisa ser desenvolvido por um homem que seja ordeiro e submisso conforme apregoou Adam Smith em 1776 na sua obra A Riqueza das Nações (1982), colocando esta condição como natural, no entanto, esta condição, foi retomada por Karl Heinirich Marx em 1844, nos Manuscritos Econômico-Filosóficos (2004), indicando que era o processo histórico do trabalho o determinante do estranhamento da classe trabalhadora em relação a si e aos outros e em relação à realidade. 
No ano de 1861, Karl Marx, no Capital (2004), aprofundou essa condição subjetiva afirmando que os homens se coisificam enquanto os objetos se humanizam, descrevendo o fetiche da mercadoria. É em virtude desse estranhamento e do fetichismo promovido pelo atual modo de reprodução econômico-político e reprodução social que os homens não conseguem perceber que o capital precisa do trabalho para se manter enquanto o trabalho não precisa do capital para se sustentar. Desta forma evidencia-se a contradição, pois enquanto Adam Smith (1982) preconiza o homem ordeiro e submisso, Marx (2007) o designa como ser social estranhado, isto é, o homem egoísta, traiçoeiro e covarde que o capital precisa ter como traços da subjetividade humana para se reproduzir econômica e socialmente:

Somente numa sociedade que supere a divisão do trabalho e a propriedade privada dos meios de produção fundamentais pode-se pensar que todas as possibilidades do desenvolvimento do ser social se tornem acessíveis a todos os homens (NETTO e BRAZ, 2007, p.46).

Com isto, o atual modo de produção estará produzindo riqueza de forma desigual e combinada com a miséria. As crises de superprodução do capital representam o desfecho de um ciclo. Manter a atual subjetividade inautêntica (TERTULIAN, apud ANTUNES, 2001) é de suma importância para manter o atual modo de produção. Considerar o outro como um objeto que pode ser traído de forma covarde é uma subjetividade inautêntica, estranhada, necessária para a competitividade. Afinal, para se alcançar a vitória, a mais valia, vale tudo. Seja mudar as regras no meio do jogo, seja aumentando o número de indigentes como nos assevera Martins:
O número oficial de pobres dos Estados Unidos subiu para 43.6 milhões de pessoas, o maior dos últimos 51 anos em que esse levantamento oficial é realizado. Um em cada sete norteamericanos está abaixo da linha oficial de pobreza, definida pelo governo como o teto de renda mensal de 1.830 dólares (cerca de 3.000 reais) para uma família de quatro pessoas (MARTINS, 2010).

Assim entende-se que as condições da economia-política sob a égide do capital são fundantes de toda subjetividade ordeira, submissa, egoísta, traiçoeira, zcovarde e estranhada predominante na atual reprodução social.

\section{As relações entre a singularidade e a universalidade no filme sonhos no gelo}

Se a ética não é um conjunto abstrato de valores, mas um complexo valorativo que expressa relações sociais que superam a antinomia entre o indivíduo e a sociedade, não é difícil percebermos que a ética nem sempre é possível. (LESSA, 2007,p.23).

No filme Sonhos no Gelo observamos diversas contradições entre a técnica de patinação do gelo e a formação de suas atletas assim como com as mediações das famílias dessas. Num contexto estadunidense da década de 2000, as contradições identificadas precisam ser refletidas de acordo com a história dessa nação que remete ao entendimento das condições econômicas , as quais garantem a sua reprodução social, e também das condições extraeconômicas, no caso em questão a ética.

Caso entendamos que o trabalho é a categoria fundante dos homens, conforme apregoa Lukács (1979), numa sociedade regida pelo capital predominantemente o 
homem não se reconhecerá no trabalho que realiza. Com isso torna-se estranho em relação à si, estranho em relação aos outros e estranho em relação à realidade. Isso faz com que o homem torne objeto e o objeto torna-se o sujeito e com isso comandando as ações que o homem deve ter ao longo de sua vida. Isso pode ser entendido por meio das relações reificadas as quais numa sociedade regida pelo capital predomina-se o ter mais ao invés de ser mais. Daí, passamos a nossa vida trabalhando arduamente para obter um salário e com isso comprarmos as mercadorias que nos dão prazer. Todavia, assim que as compramos o fetiche, o feitiço se acaba, e começamos a alimentar uma nova ilusão a ser comprada.

Isso nos remete aos valores que uma das famílias do filme "Sonhos no Gelo" possui. Vejamos a cena:

Tina: - Os vencedores fazem sacrifícios! (11 min 33s)

Jennifer: - Ou talvez apenas trapaceiem. $(11 \min 35)$

Contextualizando: Quando Casey apresenta o recital e passa para o nível júnior e fica empolgada em se tornar uma atleta em patinação e a treinadora Tina apresenta vários fatores contra.

Tina: - Você precisa de um técnico, balé, coreógrafo, um tempo privado na pista.

- Os pais da Nikki refinanciaram a casa para conseguirem isso para ela.

- E o pai da Tiffany trabalha em dois empregos, (31 min 6s)

Cenas da Casey de acordar, ir para escola, malhar, trabalhar e patinar (44min20s/45min24s)

Contextualizando: Nikki comenta que conseguiu patrocínio da Toyota e da . Slunkys, nisso a Tiffany comenta.

Tiffany: - Estamos ficando para trás no marketing.

Pai de Tiffany: - Estou trabalhando em dois empregos para você, querida, porque você vale a pena. E vai valer mais ainda quando ganhar! (49min15s)
As transcrições das cenas acima nos revelam alguns indícios das condições objetivas formadoras das condições subjetivas sob a égide do capital. Observemos que os pais de uma atleta refinanciaram seu imóvel e, além disso, trabalham em dois empregos. Afinal, os vencedores fazem sacrifício [sic!!!]. Vejamos que tudo é mercadoria numa sociedade regida pelo capital. Seja as questões objetivas (feijão, arroz, casa, entre outras) e também as questões subjetivas (um técnico de balé, um coreógrafo, uma profissional do sexo, entre outras) (MARX, 2004a). Constatamos que para se fazer uma atleta campeã são necessários a compra de diversas mercadorias. E, além disso, fica subentendido aqui nesse momento a necessidade de se trapacear. Afinal numa sociedade regida pelo capital predominantemente os homens precisam ser egoístas, traiçoeiros e covardes. Isso é mais um indício para pensarmos com o Lessa (2007) de que a ética não será possível nas relações humanas sob a égide do capital.

Mas no decorrer do filme as mediações que a técnica vai realizando com suas atletas vão demonstrando os aspectos fundantes da atual sociabilidade regida pelo capital. A conquista de uma vitória faz com que o caráter da competição seja superado a favor da competitividade. Entendemos aqui a competitividade com um sacrifício humano para obter a plenitude da sua singularidade, a qualquer preço. Seja fazendo uso de doping, comprando juízes, comprando atletas para se empenharem num jogo, enfim a busca da vitória com a competitividade é um exemplo de como os aspectos universais são relegados a favor da singularidade egoísta, traiçoeira e covarde. Nesse sentido, mais uma cena vai corroborando as contradições que observamos na atual sociabilidade na 
qual os seus valores predominantemente se fazem presentes em todas as instituições inclusive no esporte. A cena apresentada nos possibilitou esta reflexão.

Observamos que o trabalho estranhado sob a égide do capital, trabalho esse que é uma tortura, se faz presente aqui nas mediações observadas entre a técnica com suas atletas. Este trabalho promove uma divisão social entre quem pensa e aquele que executa.

O trabalho humano faz com que seja estabelecida uma finalidade. Para cumprir essa finalidade o homem elabora diversas alternativas. E uma delas será escolhida de acordo com os valores predominantes. (LESSA, 2002, 2007 LUKÁCS, 2010). Deste modo, a finalidade de obter uma vitória, com a alternativa a qualquer custo, faz com que os valores egoístas, traiçoeiros e covardes, predominantes sob a égide do capital, estejam presentes na cena abaixo constatada.

$4^{\circ}$ CENA

$4^{\circ}$ Cena a trapaça - troca de patins para atleta perder (a prática critério da verdade)

Tina: casey, você quase perdeu um dos patins

- C: eu sei, ele está cedendo.

- T: acho melhor vir comigo $\left(59^{\prime}: 23^{\prime \prime}\right)$. (contexto da compra dos patins, até ela descobrir que não se pode usar patins novos em competição).

- C: que tipo de gente vocês são? $\left(1: 03^{\prime}: 25^{\prime \prime}\right)$

Quando a técnica compra de patins novos dando-os "de presente" a sua atleta para usa-lo numa final da competição, sabendo que era impróprio e que isto reduziria o seu desempenho, não podemos deixar de pensar com Karl Marx (2007) deque a prática é o critério de verdade. A prática social sob a égide do capital faz com que os homens se tornem objetos, coisifica-os. Ao nos tornarmos coisificados em relação às finalidades por nós elaboradas, somos capazes de fazer uso de qualquer alternativa para vencer. Inclusive boicotar a própria atleta para que outra atleta, no caso a filha, pudesse ter êxito nas seletivas e ser indicada para concorrer ao campeonato nacional.

Por fim observamos mais uma cena que nos faz entender como a mercadoria comanda as relações sociais sob a égide do capital a ponto de intensificar a nossa condição de estranhos a nós mesmos e estranhos à realidade. No encerramento do filme a técnica parece demonstrar certo arrependimento pelo ato ilícito que cometeu com sua atleta. Porém a sua substância histórica, com seus valores conservadores, faz com que seu passado volte ao presente como um fantasma. Ao dialogar com a mãe da atleta por ela boicotada a respeito do patrocínio, mais uma vez os valores que comandam as escolhas das nossas alternativas em pró de uma finalidade voltam à cena. Observemos:

\section{$1^{\prime} 32^{\prime} 43^{\prime \prime}$ até 1'33'48'}

Mãe da Casey: Você sabe que eu não posso pagar. Precisamos de um patrocinador.

Tina: Tenho um em vista. O Super Burger quer.

Mãe Casey: O Super Burger?! Ah não, não, absolutamente não!

Tina: Por quê não?

Mãe Casey: Olha, se ela não pode comer, ela então também não pode endosar, temos que procurar uma coisa mais saudável, que tal um fabricante de granola?

Tina: Granola? Que tal óleo de rícino? Mãe Casey: Isso é porque eu sou a mãe dela. O que eu disser vale a pena. Ela é minha filha.

Tina: Ela é minha patinadora.

Mãe Casey: Filha vale mais que patinadora. Pergunte a qualquer um. 
Tina: Pergunte a qualquer atleta profissional, o treinador sempre ganha da mãe, sempre.

Ou seja, a atleta para a treinadora é uma mercadoria, um objeto para o seu sonho de campeã. E essa mercadoria precisa de outras mercadorias para intensificar o seu valor de troca, já que aparenta ter um alto valor de uso, afinal ela é talentosa como patinadora. Para intensificar o seu valor de troca vale qualquer patrocínio, inclusive de uma industria de alimentos a qual não seja usado pelo consumo da atleta ou de empresas que intensificam a extração de mais valia relativa, empobrecendo a classe trabalhadora, e contribuindo com a atual crise estrutural do capital.

\section{CONSIDERAÇÕES FINAIS}

Podemos constatar no filme que o projeto de conquista da singularidade da vitória a qualquer preço pela técnica constitui-se num valor predominante sob a égide do capital. Essa iniciativa não pode ser considerada uma prerrogativa da competitividade esportiva. Com o atual modo de produção que preconiza a elaboração de forma desigual e combinada entre a riqueza e a miséria, ou seja, só há produção de riqueza se houver produção intensificada de miséria, leia-se aumento do desemprego, aumento do trabalho temporário, aumento do uso do seguro desemprego. Esse modo de produção faz com que tenhamos uma subjetividade inautêntica (ANTUNES, 2001). Essa subjetividade inautêntica faz-nos estranhos a nós mesmos, estranhos aos outros e estranhos em relação à realidade coisificando-nos.
Assim, quando o projeto singular se sobrepõem ao projeto universal a condição egoísta, traiçoeira e covarde dos homens se intensificam em sua prática social. Para Marx podemos entender que o seu projeto universal se resume no desenvolvimento humano o qual a condição sine qua non exige a redução da jornada de trabalho da classe trabalhadora, a superação do estado, a superação do capital e a superação do trabalho estranhado (MÉSZÁROS, $2002,2004)$. Sob a égide do capital, poucos são os homens que conseguem se desenvolver humanamente. As condições objetivas postas para a humanidade fundamentadas na propriedade privada dos meios de produção intensificam que homens e mulheres busquem conquistar a sua singularidade apoiado em valores desumanos. Mas isso é a sociedade regida pelo capital. Assim nos apoiamos em Mészáros (2002) que nos assevera: ou a humanidade acaba com o capital ou o capital destruirá a humanidade.

Com efeito, entendemos que sob o atual modo de produção e reprodução social a ética dificilmente poderá conduzir as mediações humanas. Seja no esporte ou em qualquer outra prática social.

\section{REFERÊNCIAS}

ANTUNES, Ricardo. Os Sentidos do Trabalho: Ensaio sobre a afirmação e a negação do trabalho. $5^{\circ}$ ed. São Paulo: Boitempo, 2001.

BOTTOMORE. T. Dicionário do pensamento marxista. Rio de janeiro: Jorge Zahar Editor, 1983.

FEDERAÇÃO PORTUGUESA DE DESPORTO NO GELO. Patinagem artística no gelo. Disponível em: < http:// www.fpdg.com/category/modalidades/ 
patinagemartisticanogelo/ > Acesso em: 27 de set/2010 .

KOSIK, Karel. O Homem e a Filosofia. In Humanismo Socialista. Portugal. Edições 70.1968.

LESSA, Sérgio. Lukács. Ética e Política: Observações acerca dos fundamentos ontológicos da ética e da política. Chapecó: Argos. 2007c.

LESSA, Sergio. Mundo dos homens. Trabalho e ser social. São Paulo: Boitempo, 2002.

LUKÁCS, Gyorgy. Introdução a uma estética marxista. Editora Civilização Brasileira. Rio de Janeiro. 1978.

LUKÁCS, Gyorgy. Ontologia do ser social: Os princípios ontológicos fundamentais de Marx. São Paulo: Livraria Editora Ciências Humanas, 1979.

LUKÁCS, Gyorgy. Prolegomenos para uma Ontologia do Ser Social. São Paulo. Editora Boitempo. 2010.

MARQUES JUNIOR, Waldemar. Esporte Escolar e Emancipação Humana. Reflexões à Luz da ontologia marxiana. 2012.264f.Tese. (Doutorado em Educação) Faculdade de Educação. Unesp. Araraquara. 2012.

MARTINS, José. A Bolha Keynesiana. Crítica Semanal da Economia. Núcleo de Educação Popular-13 de maio. São Paulo. SP. Ano XXII no 969, abril. 2009
MARTINS, José. Império do Terror: Estados Unidos, ciclos econômicos e guerras no início do século XXI. São Paulo: Editora Instituto José Luis e Rosa Sundermann. 2005.

MARTINS, José. Pobreza Americana. Crítica Semanal da Economia. São Paulo. SP. Setembro, 2010 p. 2

MARTINS, L. M. As aparências enganam: divergências entre o materialismo histórico dialético e as abordagens qualitativas de pesquisa. Caxambu, 2006. Disponivel em: <www.anped. org.br/reunioes/29ra/trabalhos/trabalho/ GT17-2042--int.pdf> . Acesso em: 09 de set, 2010.

MARX, Karl. O Capital: crítica da economia política: Livro I. v.1. Rio de Janeiro:Civilização Brasileira. 2004a.

MARX, Karl; ENGELS, Friederich. A ideologia alemã. Rio de Janeiro: Civilização Brasileira, 2007.

MÉSZÁROS, István. O poder da ideologia.

São Paulo: Boitempo, 2004.

MÉSZÁROS, István. Para além do capital.

Rumo a uma teoria da transição. São

Paulo: Editora da Unicamp; Boitempo, 2002.

NETTO, José Paulo; BRAZ, Marcelo.

Economia política: uma introdução crítica. São Paulo: Cortez, 2007.

SMITH, Adam. A riqueza das nações. v. II. São Paulo: Abril Cultural, 1982. 
DREAMS IN (DE) ICE: a film analysis perspective a esthetic Luckacs

\begin{abstract}
The central aim of this study is to perform the analysis of the film "Ice Dreams" by American director Tim Fywell (2005), from the Marxist aesthetics proposed by Georg Lukács (1978). This objective is developed from the research project of "audio source imagery." The study has a qualitative character, which through an interpretative synopsis, seeks to bring the categories of universality, uniqueness and particularity of Lukács as a basis for reflection and interpretation. Above all, we intend to analyze this film is to promote subsidies for teacher reflection, contextualized the issue of sport, the school, the teacher / coach / student / knowledge in a society governed by capital through film analysis.
\end{abstract}

Key-words: Sport; Capitalism; Cinema; Ethics.

Recebido em: outubro/2013

Aprovado em: fevereiro/2014 